\title{
Accounting for the decline in Spanish household expenditures inequality during the 1980s
}

\author{
Coral del Rio ${ }^{1}$, Javier Ruiz-Castillo ${ }^{2}$ \\ 1 Departamento de Economía Aplicada, Universidad de Vigo, campus Lagoas-Marcosende s/n, \\ 36200 Vigo, Spain \\ 2 Departamento de Economía, Universidad Carlos III de Madrid, Madrid, 126, 28903 Getafe \\ (Madrid), Spain
}

\begin{abstract}
In this paper we apply decomposition methods to analyze some of the factors accounting for the decrease in household expenditures inequality in Spain during the 1980s. We adopt a simple one-parameter model in which equivalence scales depend only on household size. Then we propose an inequality decomposition method which minimizes equivalence scales' potential contamination problems. We find that most of the change in overall inequality is due to a reduction in the within-group term in the partition by household size. The bulk of this reduction is accounted for by changes at the lower tail of the distribution in the partitions by the socioeconomic category and educational level of the household head. These two findings are independent of the equivalence scales parameter.
\end{abstract}

\section{JEL classification: D31}

Key words: Inequality decomposition, inequality trend, equivalence scales

\section{Introduction}

The increasing availability of microeconomic data on the income distribution in countries all over the world, has made possible the appearance of a vast literature on intertemporal comparisons of income inequality within specific countries during the last 25 years. There are several reasons why the Spanish case is an

This work has been completed under the research programme of the Cátedra Gumersindo de Azcárate, financed by the Ministry of Labour and Social Affairs. It has been presented in the 1996 meeting of the network "Distribution and Redistribution of Income", in Bordeaux, financed by European Communities (Contract \#ERBCHRXCT940647). Financial help from Project PB96-0118 of the Spanish DGES is also acknowledged. Comments by two anonymous referees have helped to improve very much the original version of the paper. 
interesting one. At the political level, Spain became a democracy during the mid1970s and a full member of the European Union in 1986, while at the economic level it became involved in a complex process of economic modernization and liberalization resulting in a more open and market oriented economy. At the same time, Spain took important steps towards a fairly comprehensive safety net in an attempt to catch up in the construction of a Welfare State comparable to those existing in other Western societies. In so doing, both the direct and the indirect tax systems were profoundly modified. Thus, a modern and rather progressive income tax system was put in place in 1978, while the EU membership led to the introduction of a value added tax system together with the suppression of a number of ad valorem indirect taxes.

In the midst of these transformations, how did income inequality evolve in Spain during this period? As in Portugal, which has gone through similar political and economic reforms in essentially the same time frame, Spain saw a decrease in both household income and expenditures inequality, a different trend from many OECD countries ${ }^{1}$. From this perspective, the Iberian peninsula's experience could be of interest to other economies in transition, in Latin America as well as in Eastern Europe. However, in order to draw relevant lessons we need a full understanding of the mechanisms which have made possible the compatibility between such a significant process of political and economic reform and the reduction in household income and expenditures inequality. This paper makes a contribution in this direction, applying decomposable methods to analyze some of the factors accounting for the decline in Spanish household expenditures inequality during the 1980s. The data used are the 1980-1981 and 1990-1991 Encuestas de Presupuestos Familiares (EPF for short), the budget surveys collected by the INE (Instituto Nacional de Estadística) with the main purpose of estimating the weights of the official consumer price index.

For every population partition, decomposable measures of inequality allow us to express overall inequality in a crosssection as the sum of two terms: a weighted sum of within-group inequalities, plus a between-group inequality component. In this paper, the between-group component is calculated as if each person within a given group received the group's mean income ${ }^{2}$. On the other hand, in a heterogeneous world where households with different characteristics have different needs, the first order of business is to decide "who are the equals". This leads to what we call the basic partition formed by ethically homogeneous subgroups within which income is directly comparable. Then comes a rule to perform interpersonal welfare comparisons across heterogeneous subgroups. To simplify the analysis, researchers usually engage in decomposability exercises for the distribution of

\footnotetext{
${ }^{1}$ For the 1980s and Portugal, see Gouveia and Tavares (1995) and Rodrigues (1993); for Spain, see Del Río and Ruiz-Castillo (1996, 2001), Alvarez et al. (1996) and Pena (1996); and for the international experience, see, for instance, Atkinson et al. (1995) and Gottschalk and Smeeding (1997). As a matter of fact, the inequality reduction in Spain has been taking place since 1973-1974 - see Ruiz-Castillo (1995b, 1998), and INE (1996).

2 The seminal papers on inequality decomposition are Bourguignon (1979) and Shorrocks (1980, 1984). For recent discussions of the issues involved in decomposition analysis, see Cowell and Jenkins (1995) and Ruiz-Castillo (1995a).
} 
equivalised income according to a single equivalence scale ${ }^{3}$ However, as Coulter et al. (1992a) conclude, there is no single 'correct' equivalence scale for adjusting incomes. Thus, a range of scale relativities is both justifiable and inevitable. This, of course, might affect the results and will complicate the decomposition analysis.

In this paper, we propose an inequality decomposition method in three steps which minimizes the complications induced by the use of a wide range of equivalence scales. In the first place, to make the analysis tractable we adopt the simplest admissible equivalence scale model, first used by Buhmann et al. (1988) and Coulter et al. (1992a, b). In this model, the only household characteristic which gives rise to differences in needs is household size, and different assumptions about the importance of economies of scale in consumption are represented through a single parameter. In the second place, we select the mean logarithmic deviation as our decomposable index. In this way, when we restrict ourselves to the basic partition by household size, we can express overall inequality as the sum of a within-group term, independent of the equivalence scale parameter (the uncontaminated term), and a between-group term which captures all the consequences of making interpersonal welfare comparisons according to a range of equivalence scale parameter values (the contaminated term). In the third place, we study non-basic partitions in a novel way by applying the decomposability of our inequality index to the uncontaminated term. As a result, this term is seen to be equal to a within-group and a between-group term for each non-basic variable which captures solely the orthogonal effects with respect to household size.

As far as the analysis of the inequality trend, the procedure presents the following two advantages. (i) For any non-basic partition we can decompose the inequality trend into four terms. The first three terms are independent of the equivalence scale parameter: a) the change in within-group inequality (due to changes in subgroup inequality values), b) the change in between-group inequality (due to the relative variations in subgroup means), and c) the demographic change across partition subgroups (due to shifts in subgroup population shares). The fourth term, capturing the changes in the contaminated term (due to the relative variations in household size subgroup means), is the only one dependent on the assumptions we make about the importance of economies of scale. (ii) The results for the total population can be easily related to the ones at the specific subgroup level for both the basic and the non-basic partitions. In a context where a considerable part of the trend in overall inequality is accounted for by changes in within-group inequality, it is important to know which specific subgroups are contributing positively and negatively to a given change in this term.

\footnotetext{
3 See, for example, Jenkins (1995) and Borooah and Collins (1995) for the UK, Gouveia and Tavares (1995) and Rodrigues (1993) for Portugal, Tsakloglou (1993) for Greece, and Jäntti (1997) for international comparisons using the LIS data base. In the seminal contribution to decomposition analysis, Mookherjee and Shorrocks (1982) study the evolution of unadjusted household income by age of household using published UK group data from the Family Expenditure System; therefore, no equivalence scale is considered at all.
} 
The main findings are as follows. According to the mean logarithmic deviation, household expenditures inequality in Spain decreases during the 1980s by 8 to $10 \%$ depending on the value of the equivalence scale parameter. Most of this variation is due to a reduction of $10.3 \%$ in the uncontaminated term. In turn, the bulk of this change can be accounted for by the changes occurring in the partitions by the socioeconomic category and the educational level of the household head. This is especially the case at the lower tail of the distribution, occupied by households headed by a retired person or someone belonging to the agricultural categories, in the first partition, or by an illiterate or a person without formal studies in the second one.

The paper is organized in five sections. In Sect. 2, we present the decomposition method, emphasizing both its strengths and its limitations in empirical applications. In Sect. 3 we describe the data. In Sect. 4 we present a brief description of the macroeconomic evolution of Spain during the 1980s and report our results accounting for the trend in expenditure inequality in terms of the partition by household size and five other household characteristics. Section 5 summarizes the paper and discusses the main results.

\section{The decomposition method}

\subsection{Interpersonal comparisons of welfare}

Assume we have a population of $\mathrm{h}=1, \ldots, \mathrm{H}$ households whose living standards can be adequately represented by a one-dimensional variable we call income, $x^{h}$. Households can differ in income and/or a vector of household characteristics. As indicated in the Introduction, we assume that equivalence scales depend only on the number of persons in the household. Households of the same size are assumed to have the same needs and, therefore, their incomes are directly comparable. Larger households have greater needs, but also greater opportunities to achieve economies of scale in consumption. Assume that there are $\mathrm{m}=1, \ldots, \mathrm{M}$ household sizes in what we call the basic partition. Following Buhmann et al. (1988) and Coulter et al. (1992a, b), for each household $h$ of size $m$ we define equivalised income by

$$
z^{h}(\Theta)=x^{h} / m^{\Theta}, \Theta \in[0,1] .
$$

When $\Theta=0$, equivalised income coincides with original household income, while if $\Theta=1$, it becomes per capita household income. Taking a single adult as the reference type, the expression $m^{\Theta}$ can be interpreted as the number of equivalent adults in a household of size $\mathrm{m}$. Thus, the greater the equivalence elasticity $\Theta$, the smaller the economies of scale in consumption or, in other words, the larger the number of equivalent adults ${ }^{4}$.

\footnotetext{
${ }^{4}$ As pointed out in Buhmann et al. (1988), one of the advantages of this approach is that many other models can be characterized by a certain value of $\Theta$. In particular, Jenkins and Cowell (1994) report that the McClements scale, used by Jenkins (1995) and many other authors in the UK, represents an equivalence elasticity of 0.67. On the other hand, according to Ruiz-Castillo (1998), due to the
} 
Let $\mathbf{x}^{m}$ and $\mathbf{z}^{m}(\Theta)$ be, respectively, the vector of original and equivalised incomes for households of size $\mathrm{m}$. Notice that, if $I$ is any index of relative inequality, then for each $m$

$$
I\left(\mathbf{z}^{m}(\Theta)\right)=I\left(\mathbf{x}^{m} / m^{\Theta}\right)=I\left(\mathbf{x}^{m}\right) .
$$

Thus, within each subgroup with the same needs, we assume that the inequality of equivalised income is equal to the inequality of original income, independent of individual income and prices.

This is possibly the simplest and more convenient of all interesting equivalence scale models ${ }^{5}$. Household size is undeniably a crucial characteristic underlying all models; the scheme we adopt is widely used, and it allows for a wide range of assumptions about the importance of economies of scale. Moreover, this model combines very well with the decomposition procedure we present in the next subsection in which the effects of changing the value of $\Theta$ are conveniently isolated in a single term.

\subsection{The decomposition of overall inequality for the basic partition}

We say that an inequality index is decomposable by population subgroup, if the decomposition procedure of overall inequality into a within-group and a betweengroup term is valid for any arbitrary population partition. It is well known that the GE (Generalized Entropy) family of inequality indices are the only measures of relative inequality that satisfy the usual normative properties required from any inequality index and, in addition, are decomposable by population subgroup (see the references in Footnote 2). The family can be described by means of the following convenient cardinalization:

$$
\begin{aligned}
& I_{c}(\mathbf{z}(\Theta))=(1 / H)\left(1 / c^{2}-c\right) \Sigma_{h}\left\{\left(z^{h}(\Theta) / \mu\left(\mathbf{z}^{h}(\Theta)\right)^{c}-1\right\}, c \neq 0,1\right. \\
& I_{0}(\mathbf{z}(\Theta))=(1 / H) \Sigma_{h} \log \left\{\mu\left(\mathbf{z}^{h}(\Theta)\right) / z^{h}(\Theta)\right\} \\
& I_{1}(\mathbf{z}(\Theta))=(1 / H) \Sigma_{h}\left\{\left(z^{h}(\Theta) / \mu\left(\mathbf{z}^{h}(\Theta)\right)\right\} \log \left\{z^{h}(\Theta) / \mu\left(\mathbf{z}^{h}(\Theta)\right)\right\}\right.
\end{aligned}
$$

where $\mu(\cdot)$ is the mean of the distribution. The parameter $\mathrm{c}$ summarizes the sensitivity of $I_{c}$ in different parts of the income distribution: the more positive (negative) $c$ is, the more sensitive $I_{c}$ is to differences at the top (bottom) of the distribution (Cowell and Kuga 1981). $I_{1}$ is the original Theil index, while $I_{0}$ is the mean logarithmic deviation.

Coulter et al. (1992a, b) have shown how the inequality estimates provided by the GE family vary systematically with the parameter $\Theta$ which captures the

non-linearity of the relationship between income inequality and the equivalence scale parameter $\Theta$ in Spain, the so-called OECD scale, widely used internationally, represents an equivalence elasticity of 0.4 or 0.7, approximately. Jenkins and Cowell (1994) report that the OECD scale in the UK corresponds to a value of $\Theta=0.75$.

${ }^{5}$ For two parameter empirical models which take into account household composition, see Cutler and Katz (1992) and Jenkins and Cowell (1994). For a critical survey of econometric and other methods, see Coulter et al. (1992a). 
generosity of the scale. They illustrate their analysis with UK data ${ }^{6}$. However, they suggest that using the GE family in its decomposable form restricts the 'contamination' of the inequality orderings that will arise if there is incomplete or incorrect information about the equivalence scale. In this way, some robust conclusions, independent of the equivalence scale, can be obtained.

To see this, consider the formula for the GE index when written in decomposable form for the partition by household size:

$$
I_{c}(\mathbf{z}(\Theta))=\Sigma_{m}\left[\left(v^{m}(\Theta)\right)^{c}\left(p^{m}\right)^{1-c}\right] I_{c}\left(\mathbf{z}^{m}(\Theta)\right)+I_{c}\left(\boldsymbol{\mu}^{1}(\Theta), \ldots, \boldsymbol{\mu}^{M}(\Theta)\right),
$$

where $v^{m}(\Theta)$ is the share of total equivalised income held by households of size $\mathrm{m}$ for each $\Theta ; p^{m}$ is group m's population share, and $I_{c}\left(\boldsymbol{\mu}^{1}(\Theta), \ldots, \boldsymbol{\mu}^{M}(\Theta)\right)$ is the between-group inequality calculated as if each household of a given size $\mathrm{m}$ received that group's mean equivalised income $\mu^{m}(\Theta)^{7}$. Taking into account that, for each $\mathrm{m}, I_{c}\left(\mathbf{z}^{m}(\Theta)\right)=I_{c}\left(\mathbf{x}^{m}\right)$, Coulter et al. (1992a) indicate that when $c=0$, using the 'wrong' equivalence scale only contaminates the between group component. In this case, denoting by $\mathrm{U}$ and $\mathrm{C}(\Theta)$ the uncontaminated and the contaminated terms, respectively, we have:

$$
I_{0}(\mathbf{z}(\Theta))=U+C(\Theta)
$$

where

$$
U=\Sigma_{m} p^{m} I_{0}\left(\mathbf{x}^{m}\right) .
$$

Equation (2) is the weighted average of the inequality within each household size with weights equal to population shares, and $C(\Theta)=I_{0}\left(\boldsymbol{\mu}^{1}(\Theta), \ldots, \boldsymbol{\mu}^{M}(\Theta)\right)$ is the between-group inequality which depends on $\Theta^{8}$. In order to simplify the notation, in the rest of the paper we will denote the mean logarithmic deviation, not by $I_{0}$, but simply by $I$.

\subsection{The decomposition of overall inequality for non-basic partitions}

For any non-basic partition of the population into $k=1, \ldots, K$ subgroups, the direct decomposition of overall inequality, which is the one usually applied in the literature (see Footnote 3), is:

$$
I(\mathbf{z}(\Theta))=W^{k}(\Theta)+B^{k}(\Theta)
$$

where

\footnotetext{
6 This has been confirmed in other countries. For Portugal, see Rodrigues (1993). For Spain, see Ruiz-Castillo (1995b) for the period 1973-1974 to 1980-1981, and Del Río and Ruiz-Castillo (1997a) for the period 1980-1881 to 1990-1991.

${ }^{7}$ For the connection between the inequality index cardinalization choice and the definition of between-group inequality, see Cowell and Jenkins (1995).

8 The only other member of the GE family for which the weights in the within-group term add up to one correspond to $\mathrm{c}=1$. However, the weights are given by the expression $\mathrm{v}^{m}(\Theta)$ for each $\mathrm{m}$, which depends on $\Theta$. Therefore, in this case both the within-group and the between-group terms in the decomposition depend on $\Theta$.
} 


$$
W^{k}(\Theta)=\Sigma_{k} p^{k} I\left(\mathbf{z}^{k}(\Theta)\right)
$$

is the within-group term, and

$$
B^{k}(\Theta)=I\left(\boldsymbol{\mu}^{1}(\Theta), \ldots, \boldsymbol{\mu}^{K}(\Theta)\right)
$$

is the between-group term. Unfortunately, in this case both the within- and between-group terms are "contaminated" by $\Theta$. Therefore, one cannot disentangle the impact of characteristic $k$ on overall inequality independently of the role played by the parameter $\Theta$.

To overcome this shortcoming, we suggest applying the decomposability property to the terms $I\left(\mathbf{x}^{m}\right)$ in expression (2), which are independent of $\Theta$. In other words, we propose considering the partition induced by characteristic $k$ into, say, the $K$ geographical regions in a country within each homogeneous subgroup consisting of households of equal size.

Let $\mathbf{x}^{m_{k}}$ be the unadjusted income vector of households of size $m$ in region $k$, let $\mu^{m_{k}}$ be the mean of that distribution, and let $r^{m_{k}}$ be the proportion of households of type $k$ among households of size $m$. For each $m, I\left(\mathbf{x}^{m}\right)$ is seen to be equal to the sum of two terms:

$$
I\left(\mathbf{x}^{m}\right)=\Sigma_{k} r^{m_{k}} I\left(\mathbf{x}^{m_{k}}\right)+I\left(\boldsymbol{\mu}^{m_{1}}, \ldots, \boldsymbol{\mu}^{m_{K}}\right) .
$$

The first term is the weighted sum of the inequality within each subgroup of the new partition, $I\left(\mathbf{x}^{m_{k}}\right)$, with weights equal to the demographic shares, $r^{m_{k}}$, while the second one is the between-group inequality induced by characteristic $\mathrm{k}$ among households of size $m, I\left(\boldsymbol{\mu}^{m_{1}}, \ldots, \boldsymbol{\mu}^{m_{K}}\right)$, calculated as if each household of size $m$ receives the mean of the region where one lives in, $\mu^{m_{k}}$. If we now let $p^{m_{k}}$ be the proportion of households of size $m$ in region $k$ in the population as a whole, then we have

$$
\begin{aligned}
U & =\Sigma_{m} p^{m}\left[\Sigma_{k} r^{m_{k}} I\left(\mathbf{x}^{m_{k}}\right)+I\left(\boldsymbol{\mu}^{m_{1}}(\Theta), \ldots, \boldsymbol{\mu}^{m_{K}}(\Theta)\right)\right] \\
& =\Sigma_{m_{k}} p^{m_{k}} I\left(\mathbf{x}^{m_{k}}\right)+\Sigma_{m} p^{m} I\left(\boldsymbol{\mu}^{m_{1}}(\Theta), \ldots, \boldsymbol{\mu}^{m_{K}}(\Theta)\right) .
\end{aligned}
$$

Thus, $U=W^{k}+B^{k}$, where

$$
W^{k}=\Sigma_{m_{k}} p^{m_{k}} I\left(\mathbf{x}^{m_{k}}\right),
$$

and

$$
B^{k}=\Sigma_{m} p^{m} I\left(\mu^{m_{1}}, \ldots, \mu^{m_{K}}\right) .
$$

Collecting terms, we have

$$
I(\mathbf{z}(\Theta))=U+C(\Theta)=W^{k}+B^{k}+C(\Theta) .
$$

Equation (6) is the within-group inequality in the partition by household size and characteristic $k$. On the other hand, we have seen that $I\left(\boldsymbol{\mu}^{m_{1}}, \ldots, \boldsymbol{\mu}^{m_{K}}\right)$ is the between-group inequality induced by characteristic $k$ among households of size m. Thus, Eq. (7) is the between-group inequality attributable to characteristic $k$. Of course, both Eqs.(6) and (7) capture the said effects after the effects of 
household size have been taken into account. In particular, $B^{k}$ captures the extent of between-group inequality that is orthogonal with household size. Inequality arising from the interaction of the two variables is captured in the contaminated term. Thus, the more variable $k$ is correlated with household size, the lower is the between-group inequality $B^{k}$, and the greater is the inequality arising from the interaction of the two variables which is captured in the contaminated term $C(\Theta)$. Therefore, the possibility that $B^{k}$ reveals the explanatory power of overall inequality attributed to a given characteristic $k$, once the effect of household size has been taken into account - or in other words, the possibility of disentangling what is going on in the term $B^{k}(\Theta)$ in Eq. (3) by using our decomposition procedure - is inversely related to the degree of correlation between that characteristic and household size.

To justify this procedure, we must confront the fact that, as pointed out by Borooah and Collins (1995), if two characteristics $k$ and $j$ are related, the inequality decomposition based upon the disaggregation of the population into subgroups on the basis of a single characteristic, $k$ or $j$, might be misleading. In our lexicographic procedure, we feel we are justified in selecting first household size on the grounds that it is the main variable responsible for economies of scale within the household. Then, we believe that it is useful to classify all non-basic variables according to that part of their explanatory power of overall inequality which is orthogonal to household size, and hence independent of the way we establish the interpersonal welfare comparisons which only enter through $C(\Theta)$. Thus, if for two variables $k$ and $j$ similarly correlated with household size we find that $B^{k} / U$ is much greater than $B^{\mathrm{j}} / U$, then it is reasonable to say that the population characteristic $k$ is more important as a determinant of overall inequality than is characteristic $j$.

\subsection{The decomposition of the overall inequality trend}

Let us denote by $\Delta I(\Theta)$ the change in inequality between two situations, i.e., $\Delta I(\Theta)=I\left(z_{2}(\Theta)\right)-I\left(z_{1}(\Theta)\right)$. This magnitude can be expressed as

$$
\Delta I(\Theta)=\Delta U+\Delta C(\Theta),
$$

where:

$$
\begin{gathered}
\Delta U=U_{2}-U_{1}=\Delta W+\Delta D, \\
\Delta W=\Sigma_{m} p_{1}^{m}\left[I\left(\mathbf{x}_{2}^{m}\right)-I\left(\mathbf{x}_{1}^{m}\right)\right], \\
\Delta D=\Sigma_{m}\left[p_{2}^{m}-p_{1}^{m}\right] I\left(\mathbf{x}_{2}^{m}\right), \\
\Delta C(\Theta)=I\left(\boldsymbol{\mu}_{2}^{1}(\Theta), \ldots, \boldsymbol{\mu}_{2}^{M}(\Theta)\right)-I\left(\boldsymbol{\mu}_{1}^{1}(\Theta), \ldots, \boldsymbol{\mu}_{1}^{M}(\Theta)\right) .
\end{gathered}
$$

Equation (10) is the change in uncontaminated inequality, which is seen to be the sum of two terms: Eq. (11), which is the weighted sum of inequality changes within each household size, and Eq. (12) which captures the impact of demographic changes across the partition by household size. Both are independent of 
$\Theta$, which only affects Eq. (13), namely, the change in between-group inequality in the partition by household size.

The following decomposition of the overall inequality trend for any non-basic partition $\mathrm{k}$ is useful:

$$
\Delta I(\Theta)=\Delta U+\Delta C(\Theta)=\Delta W^{k}+\Delta B^{k}+\Delta D^{k}+\Delta C(\Theta),
$$

where:

$$
\begin{aligned}
\Delta W^{k} & =\Sigma_{m_{k}} p_{1}^{m_{k}}\left[I\left(\mathbf{x}_{2}^{m_{k}}\right)-I\left(\mathbf{x}_{1}^{m_{k}}\right)\right], \\
\Delta B^{k} & =\Sigma_{m} p_{1}^{m}\left[I\left(\boldsymbol{\mu}_{2}^{m_{1}}, \ldots, \boldsymbol{\mu}_{2}^{m_{K}}\right)-I\left(\boldsymbol{\mu}_{1}^{m_{1}}, \ldots, \boldsymbol{\mu}_{1}^{m_{K}}\right)\right], \\
\Delta D^{k} & =\alpha^{k}+\beta^{k} \\
\alpha^{k} & =\Sigma_{m}\left[p_{2}^{m}-p_{1}^{m}\right] I\left(\boldsymbol{\mu}_{2}^{m_{1}}, \ldots, \boldsymbol{\mu}_{2}^{m_{K}}\right),
\end{aligned}
$$

and

$$
\beta^{k}=\Sigma_{m_{k}}\left[p_{2}^{m_{k}}-p_{1}^{m_{k}}\right] I\left(\mathbf{x}_{2}^{m_{k}}\right) .
$$

Contrary to the approximation originally suggested by Mookherjee and Shorrocks (1982) and used also by Jenkins (1995) and Jäntti (1997), Eq. (14) provides an exact decomposition of the overall inequality change ${ }^{9}$. Once the household size effects depending on $\Theta$ have been taken into account, Eqs. (15), (16) and (17) capture the contribution to the trend in uncontaminated inequality attributable to, respectively:

- the change in inequality within the double partition by household size and characteristic $k$;

- the change in between-group inequality induced by characteristic $k$;

- the demographic change across subgroups. This term reflects the impact of demographic changes in two steps. On one hand, Eq. (18) captures the shifts in population shares in the partition by household size weighted by the betweengroup inequality induced by partition $k$ among households of each size. On the other hand, Eq. (19) reflects the impact of changes across the $k$-subgroups within households of the same size, weighted by the inequality within each subgroup $k$ of size $m$.

Of course, for each partition $k$ we have that $\Delta U=\Delta W^{k}+E^{k}$, where

$$
E^{k}=\Delta B^{k}+\Delta D^{k}
$$

is the total effect attributable to characteristic $k$. If for two partitions $k$ and $j$ we find that $E^{k} / \Delta U$ is much greater than $E^{j} / \Delta U$, then it is reasonable to say that the characteristic $k$ is more important as an explanatory factor of the change in the uncontaminated term of overall inequality than is characteristic $j$.

Finally, looking at Eqs. (9) and (14), it should be emphasized that our decomposition procedure will be more useful the smaller is the term $\Delta C(\Theta)$. If

\footnotetext{
${ }^{9}$ Of course, any linear combination of base and current inequality values (or demographic shares) could be used to weight the terms in Eqs. (12), (18) and (19) (or Eqs. (11), (15) and (16), respectively).
} 
a large part of the change in overall inequality $\Delta I(\Theta)$ is due to the change in the contaminated term, $\Delta C(\Theta)$, then our effort to analize in detail the change in the uncotaminated term $\Delta U$ would be of a limited interest. Fortunately, as we will see in the empirical Sect. 4.1, in the Spanish case during the 1980s the term $\Delta C(\Theta)$ is very small indeed.

\section{The data and the background for the $1980 \mathrm{~s}$}

\subsection{The data}

We use data from the Spanish EPF for the periods April 1980 - March 1981 and April 1990 - March 1991. These are large household budget surveys of 23,972 and 21,155 sample units, representing a population of approximately 10 or 11 million households and 37 or 38 million persons in 1980-1981 and 1990-1991, respectively, occupying residential housing in all of Spain including the northern African cities of Ceuta and Melilla.

Household welfare is approximated by a measure of current consumption, namely, household total current expenditure on private goods and services, net of expenditures on the acquisition of certain durables, but inclusive of imputations for home production, wages in kind, meals subsidized at work, and the rental value for owner-occupied and other non rental housing ${ }^{10}$. Since we are interested in personal rather than household welfare, we follow the usual practice of studying the personal distribution in which each person is assigned the equivalised expenditures of the household to which she belongs - see Danziger and Taussing (1979), Cowell (1984) and Shorrocks (1995).

We express household expenditures at constant prices of the Winter of 1991 by means of household-specific statistical price indices. These are estimated by combining each household expenditure shares on a 57-dimensional commodity space with the appropriate price relatives at the national level in that space published by the INE - see Ruiz-Castillo et al. (1999) for technical details.

All of our results in the sequel use the weighting factors provided by the INE which make the sample representative of the entire population.

\subsection{The background}

From a macroeconomic point of view, the first fact that should be emphasized is that the recession which started after the first oil crisis in 1973 did not end in Spain until 1986. According to National Accounts figures, from 1980 until 1985 real GDP at 1986 prices grew only at an average annual rate of $1.4 \%$, while from that date until 1991 GDP grew at an average annual rate of $4.1 \%$. It is well known that Spain exhibits the highest official unemployment rate in the EU. During the first half of the 1980 s it rose to $21 \%$ of the labor force in 1986 ,

\footnotetext{
10 This is not the place to argue for or against expenditures versus income - on this issue see Del Río and Ruiz-Castillo (1996) and Ruiz-Castillo (1999).
} 
to be reduced later to $15.6 \%$ in 1991 . Finally, during the 1980 s, consumer price inflation in Spain was 3 percentage points above the EU average.

The EPFs which provide the data source for this paper, provide information about the rate of growth of private consumption in real terms between two points in time during the decade. Let us denote by $\mathbf{z}_{1}(\Theta)$ and $\mathbf{z}_{2}(\Theta)$ the 1980-1981 and 1990-1991 distributions of adjusted household expenditures at Winter of 1991 prices. Mean equivalised household expenditures rose in real terms at an average annual rate in the range of 2.3 to $3.3 \%$, depending on the value we give to the parameter $\Theta$.

What do we know about overall income or expenditures inequality in Spain during this period? As far as the structural aspects of inequality in a given year, some patterns already found in other countries are essentially confirmed - see Del Río and Ruiz-Castillo (1997a): i) the explanatory power of the betweengroup inequality attributable to household characteristics represents, at most, 20 to $28 \%$ of the uncontaminated term. ii) The importance of demographic variables, like household type and the age of the household head, is negligible. iii) The importance of inter-regional inequities -which explains less than $10 \%$ of uncontaminated inequality and about the same as the urban/rural variable- is smaller than the attention they receive in current debates on inequality in many countries. iv) The greatest explanatory power is provided by some socioeconomic variables, notably, the educational level and the socioeconomic category of the household head.

As far as the trend in household expenditures inequality, in Del Río and RuizCastillo (1996) we found that $\mathbf{z}_{2}(\Theta)$ Lorenz dominates $\mathbf{z}_{1}(\Theta)$ for all $\Theta$, so that there is an unambiguous decrease in relative inequality in real terms ${ }^{11}$. Using the Lorenz consistent mean logarithmic deviation, we find that real inequality decreased from 8 to $10 \%$ depending on the value of $\Theta$ - see Table 2 below.

As we will see in the next section, decomposition analysis is a useful tool in the search for an explanation of this trend. In the first place, both in Spain and in other countries, shifts in subgroup population shares are often quoted as potential determinants of inequality change. In the second place, relative variation in subgroup means may give rise to important changes in between-group inequality. In what follows, we first describe the potential explanatory factors. Then we use the decomposition of the inequality trend to verify whether or not those factors are important. In the third place, since the inequality trend unexplained through these two avenues must be necessarily accounted for by changes in specific subgroup inequality values, we check which subgroups have influenced the most (and the least) the reduction in uncontaminated inequality.

\footnotetext{
11 This result is robust to different measures of a household standard of living, including total household income.
} 


\section{The inequality trend during the 1980 s}

\subsection{The partition by household size}

For the partition by household size, Table 1 presents the information on sample sizes, the change in mean household expenditures for an intermediate value of the equivalence scale parameter, namely, $\Theta=0.4$, and the change in demographic shares which, according to Eqs. (13) and (12), affect the change in overall inequality through the terms $\Delta C(\Theta)$ and $\Delta D$, respectively. The evidence of the trend in uncontaminated, contaminated and overall inequality is presented in Table 2.

Table 1. Mean household expenditures when $\Theta=0.4$, percentage change in the number of persons during the 1980s, and personal frequency distribution in 1990-1991 in the partition by household size

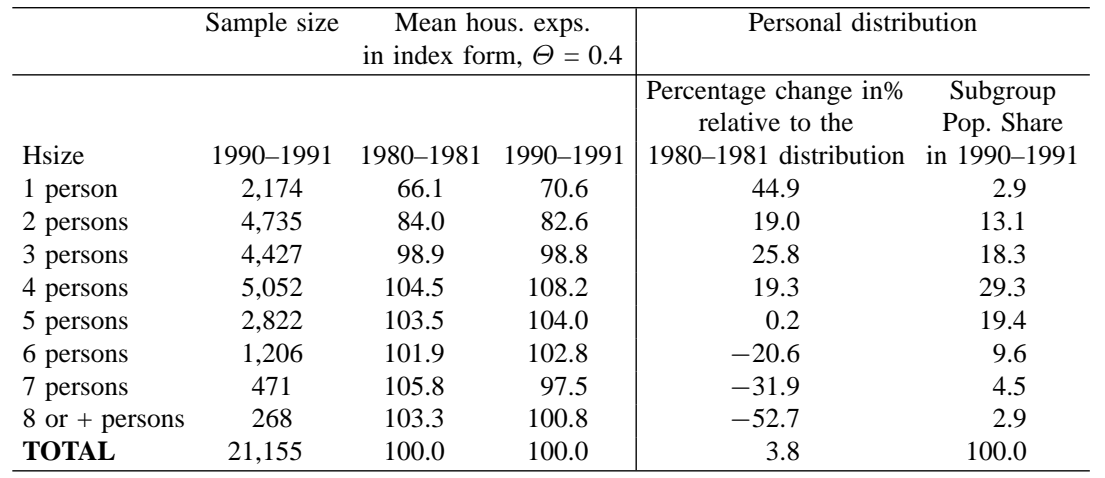

The first row in Table 2 indicates that there is a reduction in real inequality of about $8 / 10 \%$, which is rather robust to changes in the parameter $\Theta$. How do we account for this change in terms of changes inside the partition by household size? To begin with, the comparison of columns 2 and 3 in Table 1 shows that relative changes in mean household expenditures when $\Theta=0.4$ appear to be small. This is also the case for other values of $\Theta$ (not shown here). Therefore, we do not expect a large influence of $\Delta C(\Theta)$ on $\Delta I(\Theta)$ in Eq. (9). As we see in rows 2 and 4 of Table 2, when $\Theta$ grows from 0 to 1 , there is first a gradual increase in between-group inequality, which eventually becomes a decrease. In either case, in absolute terms $\Delta C(\Theta)$ accounts, at most, for only $10 \%$ of $\Delta I(\Theta)$. Thus, as expected, changes in between-group inequality in the partition by household size are of moderate importance as an explanatory factor of overall inequality. On the other hand, as indicated in row 6 of Table 2, uncontaminated inequality decreases by approximately $10 \%$. This means that most of the reduction in overall inequality - from 90 to $110 \%$ - must be attributed to the change in the uncontaminated term (see row 5 of Table 2).

The next question is to inquire as to how much of this change is due to shifts in the population frequency distribution by household size, $\Delta D$ - see Eq. (12). Taking 5 person households - whose numbers remain essentially constant - as 
Table 2. The trend in uncontaminated, contaminated and overall expenditures inequality during the 1980s

\begin{tabular}{|c|c|c|c|c|c|}
\hline & \multicolumn{5}{|c|}{ Equivalence scales parameter $\Theta$ : } \\
\hline & 0.0 & 0.2 & 0.4 & 0.7 & 1.0 \\
\hline \multicolumn{6}{|c|}{ Rate of change (in\%) relative to overall inequality: } \\
\hline $\begin{array}{l}\text { 1. Overall inequality } \\
=100 \Delta I(.) / I_{1}(.)\end{array}$ & -8.1 & -8.7 & -9.3 & -10.0 & -10.2 \\
\hline $\begin{array}{l}\text { 2. Contaminated inequality } \\
=100 \Delta C(.) / I_{1}(.)\end{array}$ & 0.5 & 0.8 & 0.8 & 0.1 & -1.0 \\
\hline $\begin{array}{l}\text { 3. Uncontaminated inequality } \\
=100 \Delta U / I_{1}(.)\end{array}$ & -8.6 & -9.5 & -10.1 & -10.1 & -9.1 \\
\hline \multicolumn{6}{|c|}{ Percentage of the change in overall inequality (in \%) accounted for by: } \\
\hline $\begin{array}{l}\text { 4. Contaminated inequality }= \\
\text { Row } 2 / \text { Row } 1=100 \Delta C(.) / \Delta I(.)\end{array}$ & -6.7 & -9.7 & -8.9 & -1.5 & 10.0 \\
\hline $\begin{array}{l}\text { 5. Uncontaminated inequality } \\
=\text { Row } 3 / \text { Row } 1=100 \Delta U / \Delta I(.)\end{array}$ & 106.7 & 109.7 & 108.9 & 101.5 & 90.0 \\
\hline \multicolumn{6}{|c|}{ Rate of change in uncontaminated inequality (in \%): } \\
\hline 6. $100 \Delta U / U_{1}$ & -10.3 & -10.3 & -10.3 & -10.3 & -10.3 \\
\hline \multicolumn{6}{|c|}{ Percentage of the change in overall inequality (in \% ) accounted for by: } \\
\hline $\begin{array}{l}\text { 7. Demographic shifts } \\
=100 \Delta D / \Delta U\end{array}$ & -13.0 & -13.0 & -13.0 & -13.0 & -13.0 \\
\hline $\begin{array}{l}\text { 8. Within group inequality } \\
=100 \Delta W / \Delta U\end{array}$ & 113.0 & 113.0 & 113.0 & 113.0 & 113.0 \\
\hline
\end{tabular}

reference in Table 1, the larger the household the larger the population decline, and the smaller the household the larger the population increase. As a result, average household size decreases from 3.70 to 3.41 members. Since these changes are undoubtedly large, we expect a noticeable influence of $\Delta D$ on $\Delta U$ according to Eq. (10). In row 7 of Table 2 we estimate that $100(\Delta D / \Delta U)=-13$. Therefore, the switch towards smaller households during the 1980s, documented in Table 1 , gives rise to a moderate increase in inequality which represents about $13 \%$ of the overall change in the uncontaminated term. Taking into account that smaller households are more unequal (although this fact is not shown here), this result comes as no surprise.

The final question is to account for the trend in the within-group term $\Delta W$ in terms of the inequality change within individual subgroups in the partition by household size. We have seen that about $113 \%$ of the reduction in the uncontaminated term must be explained within this partition. To investigate the contribution of each subgroup to the decrease in W, let us write Eq. (11) as $\Delta W=\Sigma_{m} \Delta I^{m}$, where $\Delta \mathrm{I}^{m}=p_{1}^{m}\left[I\left(\mathbf{x}_{2}^{m}\right)-I\left(\mathbf{x}_{1}^{m}\right)\right]$ and $p_{1}^{m}$ is the share of households of size $\mathrm{m}$ in the 1980-1981 personal population. In Table 3 we look at the expression $\left(\Delta I^{m} / \Delta W\right) 100$ for each $m$ in relation to $p_{1}^{m}$.

We observe that, relative to their demographic importance, the contribution to the reduction in within-group inequality by both small and very large households is very large. Households consisting of 3 members or less represent less than $30 \%$ of the population but account for more than $50 \%$ of the inequality change, while 8 or more person households represent $6.5 \%$ of the population but account for more than $20 \%$ of the inequality change. On the other hand, 4 to 6 person 
Table 3. Percentage contribution to within-group inequality in the partition by household size in comparison with each subgroup's demographic importance in 1980-1981

\begin{tabular}{lrrrrrrrrrr}
\hline \multicolumn{11}{c}{ Household size } \\
\hline & 1 & 2 & 3 & 4 & 5 & 6 & 7 & 8 & 9 and + & All \\
Contr. $=\left(\Delta I^{m} / \Delta W\right) 100$ & 6.8 & 20.9 & 23.9 & 2.2 & 17.3 & 0.02 & 8.2 & 12.0 & 8.7 & 100.0 \\
Demogr. share $=p_{1}^{M}$ & 2.1 & 11.4 & 15.1 & 25.5 & 20.1 & 12.5 & 6.8 & 3.3 & 3.2 & 100.0 \\
\hline
\end{tabular}

households, which contain almost $60 \%$ of the population, contribute only about $20 \%$ of the change.

\subsection{The explanatory role of the remaining partitions}

We have information on five household characteristics, classified into three groups: Demographic characteristics: 1) Household type (HTYPE); Geographic characteristics: 2) Size of the municipality (MUNS); 3) Autonomous Community of residence (AUTON). Socioeconomic characteristics: 4) Educational level attained by the household head (EDC); and 5) Socioeconomic status of the household head (SOCIO) $)^{12}$. For each of the five characteristics, Table 4 presents the subgroup means of household expenditures when $\Theta=0.4$, the change in the number of persons during the 1980s and, to save space, the personal frequency distribution and the mean household size (denoted $m h s$ ) for 1990-1991 only ${ }^{13}$. On the other hand, in relation to the decomposition in Eq. (14), the evidence on $\left(\Delta B^{k} / \Delta U\right) 100,\left(\alpha^{k} / \Delta U\right) 100,\left(\beta^{k} / \Delta U\right) 100,\left(\Delta D^{k} / \Delta U\right) 100$, and $\left(E^{k} / \Delta U\right) 100$ for each $k$ is presented, respectively, in columns 1 to 5 of Table 5 - see the definitions of these terms in Eqs. (16) to (19).

To begin with, as far as the mean household expenditures is concerned, the only unambiguous pattern we observe in Table 4 is the decline in the range of the index numbers when $\Theta=0.4$ for the two socioeconomic variables EDC and SOCIO. Taking into account Eq. (16), this leads us to expect a positive contribution by these variables to the reduction in the uncontaminated inequality during this period. Indeed, as we observe in column 1 of Table 5, the socioeconomic variables EDC and SOCIO make a large positive contribution to the reduction in uncontaminated inequality. On the other hand, the variables AUTON and HTYPE have effects of some relevance in the opposite direction.

Our next question is the impact of demographic factors captured in the term $\Delta D^{k}$. In Eq. (17) we have seen that $\Delta D^{k}=\alpha^{k}+\beta^{k}$. We shall start by the term

\footnotetext{
${ }^{12}$ We have also examined two other possibilities: the age of the household head, and the number of earners of labor and non-labor (mainly, public transfers) income. Since the results indicated that these variables add very little to the analysis - see Del Río and Ruiz-Castillo (1997a) - we have omitted these variables in this paper.

${ }^{13}$ We have tried to preserve the maximum heterogeneity in each partition. Therefore, some of the subgroups might have a small sample size which will affect the reliability of individual results. The minimum sample size in each partition are the following. HTYPE: 598 (households without a couple and minors); AUTON: 221 (Ceuta y Melilla); TMUN: 1944 (above 500,000 inhabitants); SOCIO: 50 (living off property income); EDC: 914 (more than 3 years College degree); HSIZE: 268 (8 or more persons).
} 
Table 4. Mean household expenditures when $\Theta=0.4$, percentage change in the number of persons during the 1980s, and personal frequency distribution in 1990-1991 in the different non-basic partitions

\begin{tabular}{|c|c|c|c|c|c|}
\hline \multirow[b]{3}{*}{ EDC } & \multirow{2}{*}{\multicolumn{2}{|c|}{$\begin{array}{l}\text { Mean house. expends. } \\
\text { in index form, } \Theta=0.4\end{array}$}} & \multicolumn{3}{|c|}{ Personal distribution } \\
\hline & & & \multirow{2}{*}{$\begin{array}{l}\text { Percentage change } \\
\text { in } \% \text { relative } \\
\text { to the } 1980-1981 \\
\text { distribution }\end{array}$} & \multirow{2}{*}{$\begin{array}{c}\text { Frequency } \\
\text { distribution } \\
\text { in 1990-1991 }\end{array}$} & \multirow{2}{*}{$\begin{array}{c}\text { mhs in } \\
1990-1991\end{array}$} \\
\hline & 1980-1981 & 1990-1991 & & & \\
\hline Illiterate & 61 & 62 & -42.1 & 3.5 & 2.69 \\
\hline $\begin{array}{l}\text { Without formal } \\
\text { studies }\end{array}$ & 76 & 76 & -18.2 & 19.7 & 3.14 \\
\hline Grade School & 97 & 92 & -15.8 & 39.4 & 3.50 \\
\hline Primary School & 122 & 103 & 133.1 & 15.1 & 3.68 \\
\hline Secondary School & 151 & 127 & 59.4 & 7.4 & 3.39 \\
\hline Vocational School & 129 & 115 & 260.1 & 5.4 & 3.56 \\
\hline $\begin{array}{l}3 \text { years College } \\
\text { degree }\end{array}$ & 161 & 143 & 41.3 & 4.7 & 3.47 \\
\hline $\begin{array}{l}>3 \text { ys. College } \\
\text { degree }\end{array}$ & 197 & 188 & 38.8 & 4.8 & 3.52 \\
\hline ALL & 100.0 & 100.0 & 3.8 & 100.0 & 3.41 \\
\hline \multicolumn{6}{|l|}{ SOCIO } \\
\hline $\begin{array}{l}\text { Agricultural } \\
\text { workers }\end{array}$ & 70 & 75 & -35.3 & 3.3 & 4.03 \\
\hline $\begin{array}{l}\text { Agricultural } \\
\text { self-employed }\end{array}$ & 75 & 81 & -47.6 & 3.1 & 3.89 \\
\hline $\begin{array}{l}\text { Non-agricultural } \\
\text { workers }\end{array}$ & 107 & 101 & -10.5 & 38.5 & 3.91 \\
\hline $\begin{array}{l}\text { Non-agricultural } \\
\text { self-employed }\end{array}$ & 104 & 110 & 13.2 & 8.4 & 3.95 \\
\hline $\begin{array}{l}\text { Supervisors and } \\
\text { Armed Forces }\end{array}$ & 121 & 131 & 44.6 & 3.5 & 3.99 \\
\hline Upper classes* & 175 & 155 & 33.7 & 9.1 & 3.79 \\
\hline $\begin{array}{l}\text { Unclassified } \\
\text { active persons }\end{array}$ & 106 & 108 & -5.0 & 0.4 & 3.95 \\
\hline $\begin{array}{l}\text { Part time (less } \\
\text { than } 1 / 3 \\
\text { working day) }\end{array}$ & 82 & 101 & -38.1 & 1.2 & 3.55 \\
\hline Unemployed & 73 & 78 & 1.7 & 5.5 & 3.73 \\
\hline $\begin{array}{l}\text { Early retired } \\
\text { (before } 65 \\
\text { years of age) }\end{array}$ & 80 & 90 & 61.0 & 9.6 & 3.26 \\
\hline Retired, male & 73 & 81 & 51.5 & 12.1 & 2.55 \\
\hline Retired, female & 62 & 67 & 65.9 & 3.4 & 1.55 \\
\hline $\begin{array}{l}\text { Living off } \\
\text { property income }\end{array}$ & 98 & 128 & -28.0 & 0.2 & 2.31 \\
\hline $\begin{array}{l}\text { Other people } \\
\text { outside of the } \\
\text { labor force }\end{array}$ & 93 & 77 & 10.6 & 1.7 & 2.69 \\
\hline ALL & 100.0 & 100.0 & 3.8 & 100.0 & 3.41 \\
\hline
\end{tabular}

* Entrepeneurs with salaried workers, professionals, agricultural and non-agricultural firm executives, public Administration high officials 
Table 4. (continued)

\begin{tabular}{|c|c|c|c|c|c|}
\hline HTYPE & & & & & \\
\hline Single person & 66 & 71 & 44.7 & 2.9 & 1.00 \\
\hline Couples & 84 & 83 & 19.1 & 10.0 & 2.00 \\
\hline $\begin{array}{l}\text { Three or } \\
\text { more adults }\end{array}$ & 92 & 92 & -5.1 & 3.9 & 2.60 \\
\hline $\begin{array}{l}\text { Couples with } \\
\text { young (18-30 years } \\
\text { old) descendants }\end{array}$ & 111 & 115 & 75.4 & 17.4 & 3.66 \\
\hline $\begin{array}{l}\text { Couples with } \\
\text { minors (less than } \\
18 \text { years old) }\end{array}$ & 101 & 98 & -15.9 & 28.5 & 3.93 \\
\hline $\begin{array}{l}\text { Couples with } \\
\text { minors and young } \\
\text { descendants }\end{array}$ & 108 & 107 & -1.3 & 16.0 & 5.16 \\
\hline $\begin{array}{l}\text { Couples with } \\
\text { minors and/or young } \\
\text { descendants as well } \\
\text { as older people }\end{array}$ & 101 & 103 & -15.6 & 11.3 & 5.34 \\
\hline $\begin{array}{l}\text { Single parent } \\
\text { households }\end{array}$ & 94 & 94 & 27.7 & 5.9 & 3.07 \\
\hline $\begin{array}{l}\text { Households without } \\
\text { a couple and minors }\end{array}$ & 93 & 94 & 9.1 & 4.1 & 5.19 \\
\hline All & 100.0 & 100.0 & 3.8 & 100.0 & 3.41 \\
\hline
\end{tabular}

Descendants $=$ children and/or grandchildren

\begin{tabular}{lrrrrr}
\hline TMUN & & & & & \\
\hline Under 2,000 & 80 & 77 & -34.0 & 6.5 & 3.05 \\
$2,000-10,000$ & 80 & 84 & 5.0 & 19.4 & 3.41 \\
$10,000-50,000$ & 92 & 92 & 6.9 & 22.8 & 3.53 \\
$50,000-500,000$ & 110 & 104 & 14.5 & 32.7 & 3.50 \\
Above 500,000 & 126 & 127 & 2.9 & 18.6 & 3.25 \\
All & 100.0 & 100.0 & 3.8 & 100.0 & 3.41 \\
\hline
\end{tabular}

$\alpha^{k}$. By comparing Eqs. (18) and (12), we see that the difference between $\alpha^{k}$ and $\Delta D$ is that changes in population shares are now weighted by the betweengroup inequality induced by each $k$ in the partition by household size. We have already seen that the shift towards smaller households reflected in $\Delta D$ amounts to an inequality increase which is equal to $13 \%$ of the change in uncontaminated inequality. On the other hand, it turns out that for the variables AUTON, HTYPE and SOCIO, the between-group inequality term $I\left(\boldsymbol{\mu}^{m_{1}}, \ldots, \boldsymbol{\mu}^{m_{K}}\right)$ for low values of $m$, say $m \leq 4$, is relatively small. The opposite is the case for the partitions MUNS and EDC (these results are available on request). This explains that, as we see in column 2 of Table $5, \alpha^{k} / \Delta U$ has a negative sign only for MUNS and EDC. 
Table 4. (continued)

\begin{tabular}{lrrrrr}
\hline AUTON & & & & & \\
\hline Andalucía & 85 & 86 & 8.1 & 7.8 & 3.65 \\
Aragón & 100 & 90 & 2.1 & 3.1 & 3.10 \\
Asturias & 96 & 102 & -0.3 & 2.9 & 3.26 \\
Baleares & 104 & 107 & 3.6 & 1.7 & 3.15 \\
Canarias & 91 & 94 & 8.4 & 3.8 & 3.72 \\
Cantabria & 112 & 94 & 3.9 & 1.4 & 3.46 \\
Castilla-León & 91 & 90 & 1.8 & 6.7 & 3.21 \\
Castilla-La Mancha & 75 & 83 & 4.1 & 4.4 & 3.30 \\
Cataluña & 110 & 119 & 0.6 & 15.3 & 3.27 \\
C. Valenciana & 97 & 89 & 4.2 & 9.8 & 3.29 \\
Extremadura & 69 & 72 & 6.4 & 2.9 & 3.39 \\
Galicia & 96 & 91 & 0.4 & 7.2 & 3.57 \\
Madrid & 125 & 128 & 5.4 & 12.6 & 3.41 \\
Reino de Murcia & 93 & 87 & 9.0 & 2.6 & 3.61 \\
Navarra & 122 & 120 & 2.7 & 1.3 & 3.50 \\
País Vasco & 121 & 113 & -0.1 & 5.5 & 3.45 \\
La Rioja & 96 & 95 & 1.3 & 0.7 & 3.37 \\
Ceuta y Melilla & 94 & 76 & 8.3 & 0.3 & 3.55 \\
All & 100.0 & 100.0 & 3.8 & 100.0 & 3.41 \\
\hline
\end{tabular}

The term $\beta^{k}$ depends in a direct fashion on the shifts in population shares across the subgroups of each partition $k$. What we observe in this respect in column 3 of Table 4, can be summarized as follows:

1. Fertility rates are declining, so that households with minors (HTYPE equal to 5, 6 or 7) are losing importance. Young persons (between 18 and 30 years old), heavily hit by unemployment, remain in their parents' homes rather than forming independent households of their own (HTYPE $=4)$. Single person households and couples without children, as well as single parent households (HTYPE $=1,2$, and 8, respectively), are increasing more rapidly than the population as a whole.

2. Households headed by persons with a primary school degree and beyond, are increasing, while the opposite is the case for illiterates, people without formal studies or with only grade school.

3. Households headed by someone in the agricultural sector, part-time employment, and the small subgroup living off property income are losing demographic importance. The mixed subgroup headed by supervisors or Armed Forces personnel, the upper socioeconomic category and, above all, retired people of all kinds, are increasing above the average rate.

4. Relatively large sized households are leaving small municipalities, while more people are moving into medium sized cities and provincial capitals between 50,000 and 500,000 inhabitants.

5. Only Madrid and five less developed Autonomous Communities (the Canary Islands, Andalucía, Extremadura, Murcia and Ceuta y Melilla) are growing above the national rate. Baleares Islands, Comunidad Valenciana, Castilla-La 
Table 5. The impact on the reduction in uncontaminated inequality (in percentage terms) of: (i) the change in between-group inequality induced by each partition, and (ii) demographic changes across partition subgroups

\begin{tabular}{lcrrrr}
\hline & $\begin{array}{c}\text { Between-group } \\
\text { Inequality }\end{array}$ & \multicolumn{2}{c}{ Demographic changes } & $\begin{array}{r}\text { Total } \\
\text { effect }\end{array}$ \\
\hline AUTON = Autonomous Community & $(\mathbf{1 )}$ & $\mathbf{( 2 )}$ & $\mathbf{( 3 )}$ & $\mathbf{( 4 )}$ & $\mathbf{( 5 )}$ \\
HTYPE = household type & -12.2 & 4.6 & -27.5 & -22.9 & -35.1 \\
\hline MUNS = municipality size & -19.2 & 7.1 & -23.0 & -15.9 & -35.1 \\
\hline SOCIO $=$ h. head's socioeconomic class & 22.8 & -2.2 & -12.7 & -14.9 & 7.9 \\
\hline EDC $=$ h. head's educatioonal level & 64.0 & 4.3 & -39.3 & -35.0 & 29.0 \\
\hline
\end{tabular}

(1) $=100 \Delta B^{k} / \Delta U=$ percentage change in the uncontaminated term due to the change in betweengroup inequality induced by characteristic $k ;(2)=100 \alpha^{k} / \Delta U$, equation (18); (3) $=100 \beta^{k} / \Delta U$, equation (19); (4) $=(\mathbf{2})+(\mathbf{3})=100 \Delta D^{k} / \Delta U=$ percentage change in the uncontaminated term due to shifts in population shares; (5) $=(\mathbf{1})+(\mathbf{4})=100 E^{k} / \Delta U=$ total effect attributable to characteristic $k$

Mancha and Cantabria grow close to the average rate, while the rest of the North (País Vasco, Asturias, Galicia, La Rioja) Castilla-León and Cataluña grow at a smaller rate or even lose some population.

At first, the shifts just summarized for the demographic and the socioeconomic variables - but not for the geographical ones - appear to be rather important. However, for our purpose the pertinent question is how much of the reduction in uncontaminated inequality is accounted for by these demographic changes. The evidence, reflected in the term $\beta^{k}$, appears in column 3 of Table 5. We observe that shifts in population shares within the double partition by household size and the remaining characteristics have a negative contribution to the reduction in uncontaminated inequality. Moreover, except for EDC, the term $\beta^{k}$ is large and offsets the effect captured in $\alpha^{k}$. Therefore, as shown in column 4 of Table 5, the net demographic effect on $\Delta U$ attributable to $\Delta D^{k}=\alpha^{k}+\beta^{k}$ is an increase in inequality in all cases. As far as the order of magnitude is concerned, it is of some importance for SOCIO (35\%), negligible for EDC, and between 15 and $23 \%$ of $\Delta U$ for the remaining variables.

The consequences of all of the above is reflected in column 5 of Table 5 which presents the total effect attributable to each $k$. There are two types of variables from this point of view. Those for which the increase in between-group inequality leads to an increase in uncontaminated inequality (or to a negative total effect) - AUTON, and HTYPE - and those for which the opposite is the case - SOCIO and EDC. For the first type, we must go to the contributions by individual subgroups to understand the inequality change. On the contrary, the second group of variables provides a partial but important explanation of the overall trend which amounts to one third or one half, respectively, of the reduction in uncontaminated inequality. Thus, the fact that most variables account for a small percentage of overall inequality at a given point of time does not preclude 
that some of them have a considerable effect in accounting for the trend in overall inequality ${ }^{14}$.

As we said before, Borooah and Collins (1995) point out that if two characteristics $k$ and $j$ are related, the inequality decomposition based upon the disaggregation of the population into subgroups on the basis of a single characteristic, $k$ or $j$, might be misleading. Therefore, we have created some new ones: i) the combination of the demographic variables HTYPE with the age of the household head into 16 subgroups; ii) a variable which distinguishes urban from rural municipalities in each Autonomous Community, giving rise to 36 subgroups; iii) the combination of two human capital variables, the age and the educational level of the household head, giving rise to 14 subgroups; iv) the combination of the two socioeconomic characteristics SOCIO and EDC into 16 subgroups; and v) the combination of EDC and the number of earners of labor and non-labor income into 17 categories. However, as discussed in Del Río and Ruiz-Castillo (1997a), these five characteristics do not add anything new to the analysis.

Finally, we should point out that under the usual procedure based on Eqs. (3) to (5), the impact of each non-basic partition appears mixed up with the household size effects. Therefore, the contribution of demographic shifts or changes in subgroup means would vary as a function of $\Theta$. Due to lack of space, to compare our results with those obtained with the usual procedure see Del Río and RuizCastillo (1997a).

\subsection{The explanatory role of individual subgroups}

The final question is to account for the reduction in the within-group term $\Delta W^{k}$ in terms of the change within each individual subgroup in each partition $k$. We can rewrite Eq. (15) as $\Delta W^{k}=\Sigma_{k} \Delta I^{k}$, where $\Delta I^{k}=\Sigma_{m} p_{1}^{m_{k}}\left[I\left(\mathbf{x}_{2}^{m_{k}}\right)-I\left(\mathbf{x}_{1}^{m_{k}}\right)\right]$. The information about the expressions $\left(\Delta I^{k} / \Delta W^{k}\right) 100$ and $p_{1}^{m_{k}}$ for the more important partitions - SOCIO and EDC - is in Table 6 (for the remaining partitions the information is available upon request).

For the socioeconomic category, the following subgroups account for $65 \%$ of the reduction in within-group inequality: households headed by someone in the agricultural categories or part-time employment (SOCIO $=1,2,8)$, as well as persons outside the labor force (SOCIO = 10-14). This is a large contribution by a subgroup set whose demographic importance is only one third of the population. Which subgroups contribute in the opposite direction is equally revealing. These are households headed by the unemployed and the self employed (SOCIO $=9$, 4), which have a combined contribution of $18 \%$ to the increase in within-group inequality and represent approximately that same percentage of the population.

\footnotetext{
${ }^{14}$ In spite of what he afirms in the text, Jäntti (1997) also finds effects of similar importance. For the equivalence scales implicit in the U.S. official poverty line, he reports that age of the household head accounts for 50,36 and 20\% of the change in overall inequality in Sweden, Canada and the U.S., respectively; household type accounts for $38 \%$ in Sweden, and the numeber of earners accounts for $48 \%$ in the U.K.
} 
Table 6. Individual contributions to the change in within-group inequality in selected partitions

\begin{tabular}{lrc}
\hline SOCIO & $\begin{array}{c}\text { Contribution to the } \\
\text { reduction in } \\
\text { within-group ineq. }\end{array}$ & $\begin{array}{c}\text { Personal } \\
\text { frequency } \\
\text { Distribution } \\
\text { in 1980-81 }\end{array}$ \\
\hline Workers, agricultural & 12.1 & 5.4 \\
Self-employed, agricultural & 9.8 & 62 \\
Non-agricultural workers & 52.1 & 44.6 \\
Non-agricult. self-employed & -10.6 & 7.7 \\
Supervisors and Armed Forces & 05 & 25 \\
Upper classes & 02 & 71 \\
Unclassified active persons & -01 & 0.4 \\
Part time (less than 1/3 working day) & 75 & 2.0 \\
Unemployed & -7.7 & 5.6 \\
Early retired (before 65 years of age) & 75 & 6.2 \\
Retired, male & 17.2 & 8.3 \\
Retired, female & 5.2 & 2.1 \\
Living off property income & 1.9 & 0.2 \\
Other people outside of the labor force & 4.4 & 1.6 \\
ALL & 100.0 & 100.0 \\
\hline EDC & & \\
\hline Illiterate & & 6.3 \\
Without formal studies & 11.7 & 25.0 \\
Grade School & 45.9 & 48.6 \\
Primary School & 51.9 & 6.7 \\
Secondary School & 25 & 4.8 \\
Vocational School & -5.7 & 1.6 \\
3 years College degree & 1.8 & 3.5 \\
> 3 ys. College degree & 52 & 100.0 \\
ALL & -133 & \\
\hline
\end{tabular}

For the educational level, households headed by an illiterate or a person without formal studies $(\mathbf{E D C}=1,2)$ contribute more than half of the reduction in within-group inequality but represent less than one third of the population. At the opposite extreme, we have households headed by a person who has attained a secondary school or a College degree $(\mathbf{E D C}=5,8)$ which represent $8 \%$ of the population and are only responsible for a $20 \%$ increase in inequality.

\section{Conclusions}

Inequality decomposition methods provide a useful approach to the investigation of the structure of inequality in a given year, the explanation of the inequality trend over time, and the connection between the inequality of the population as a whole and the inequality within specific subgroups. Unfortunately, in a heterogeneous world of households with different needs, we must allow for a variety of equivalence scales which may dramatically affect the results of the decomposition analysis. 
In this paper we have adopted a simple model in which equivalence scales depend only on household size through a parameter $\Theta$ which captures the importance we give to economies of scale in consumption within the household. In this context, we have proposed a decomposition method which uses the mean logarithmic deviation and minimizes equivalence scales potential contamination problems. The alternative is what we call the usual procedure in which the role of all variables is affected by the choice of equivalence scales.

The claim is that the method we propose structures and simplifies the analysis in a convenient way. Firstly, we address the partition by household size, where the complications introduced by the use of a variety of equivalence scales is isolated in the between-group inequality term. In this way, we can then concentrate on the role of the remaining variables through its effects, orthogonal to household size, which are independent of the equivalence scales.

In the empirical part of the paper we apply this method to account for the inequality trend of household expenditures in Spain between 1980-1981 and 1990-1991 at Winter 1991 prices. During this period, overall inequality decreases in the 8 to $10 \%$ range, depending on the value of the equivalence scales parameter $\Theta$. Our main findings can be organized in two groups. In the first place, the following three forces can be discarded as factors accounting for this trend:

1. The (non linear) changes in the contaminated term, caused by changes in the mean expenditures of households of different sizes, have a low explanatory power: from 90 to $109 \%$ of the change in overall inequality as a function of $\Theta$ is accounted for a reduction of $10.3 \%$ in the uncontaminated term (rows 5 and 6 in Table 2).

2. Subgroup demographic shifts in the partition by household size have a relatively small but negative effect on uncontaminated inequality: the shift towards smaller households (column 4 in Table 1), also found in other Western countries, is responsible for a $13 \%$ increase in the uncontaminated term (row 7 in Table 2).

3. Once we apply the decomposition property of our inequality measure to each household size separately, in general the demographic factor associated to non-basic partitions also causes an increase in uncontaminated inequality. Sometimes the role of a variable reinforces the demographic effect due to shifts in household sizes - as in the case of SOCIO - while in other cases the demographic effect turns out to be negligible - as in the case of EDC (columns 2 to 4 in Table 5).

In the second place, it is clear that the two key variables accounting for the reduction in uncontaminated inequality are the following:

4. As far as the variable SOCIO is concerned, households headed by a retired person have mean expenditures below the population as a whole but have improved their relative positions regardless of their age and sex. Since they have also increased their numbers, this must be the consequence of two features of the public and universal Social Security retirement system during this period: the increased scope via non-contributive pensions, and the increase in the pen- 
sions themselves, especially the minimum ones - see Boldrin et al. (1998). On the other hand, both agricultural categories, also below the average, have improved their lot as well. In this case, this is partly the consequence of their diminished population share: the decline of agricultural jobs continued undeterred during the 1980s. The other factor which should be emphasized is the entrance of Spain into the European Union. On one hand, agricultural sectors able to export (the East coast and the river valleys), have done well from 1986 onwards. On the other hand, less competitive areas (the two Castilles, Andalucía and Extremadura) have benefited from high European protection to grains, olive and wine. In the North of the country and Galicia, the livestock and milk protection system have led to anticipated retirement under acceptable economic conditions - see San Juan (1995a, 1995b).

These factors, together with the drastic relative decline in size of the upper classes, explain why SOCIO's total effect accounts for one third of the change in uncontaminated inequality. This happens through the reduction of betweengroup inequality which more than offsets the inequality increase due to the demographic factor (columns 1 and 4 in Table 5). The remaining two thirds of the reduction of uncontaminated inequality take place within the partition subgroups. In so far as households headed by a retired person or in the agricultural labor force contribute very heavily to this reduction of within-group inequality, we may conclude that the forces which lead to an increase of their mean household expenditures also cause a reduction of their inequality (Table $6)$.

5. As far as the variable EDC is concerned, only the households headed by an illiterate or a person without formal studies maintain their relative positions in mean household expenditures. All remaining subgroups lose relative ground. A fact for which, at present, we do not have a convincing explanation. Since the demographic effect does not subtract much from the total effect (colunm 4 in Table 5), the reduction in the between-group inequality is the factor responsible for fifty per cent of the reduction in uncontaminated inequality (columns 1 and 5 in Table 5). As we saw before for the SOCIO partition, the lowest educational categories are the subgroups which contribute more than proportionally to the reduction in within-group inequality (Table 6).

One useful way of summarizing the essential aspects of our analysis is to focus on what happens at both ends of the distribution. At the lower tail of the distribution (the retired and the agricultural categories, the aged, the illiterate and those without formal studies - all of which are well represented among one and two person households), there has been an increase in the mean household expenditures and an important decrease in inequality. The first fact causes a reduction in uncontaminated inequality through between-group effects; the second causes the same impact, but directly through the within-group term. In some segments of the upper tail of the distribution there has been a loss in relative positions - contributing to the between-effects already mentioned - and an increase in inequality. As a consequence, for all values of $\Theta$ the reduction in household 
expenditures inequality should be smaller for members of the GE family more sensitive to what happens at the upper tail of the distribution. This is indeed what we observe: when $\Theta=0.5$, for example, the reduction in inequality at Winter 1981 prices is equal to $-12.9,-9.6,-7.0$, and $-1.8 \%$ when $c=-1,0,1,2$, respectively - see Del Río et al. (1999).

It is worth pointing out that this is a very different pattern from the one found for the period 1973-1974 to 1980-1981, during which the decrease of household expenditures inequality is more important than during the $1980 \mathrm{~s}-$ see Ruiz-Castillo (1995b, 1998b). In particular, when $\Theta=0.5$ the reduction in inequality at Winter of 1981 prices is equal to $-20.5,-19.0,-21.1$, and $-28.5 \%$ when $c=-1,0,1,2$, respectively. This indicates that in the former period the more important changes are the ones which take place in the upper tail of the distribution. A second difference is that the geographic variables AUTON and MUNS are the ones contributing the most $(30 \%)$ to the reduction in uncontaminated inequality. The variables EDC and SOCIO account for 25 and $15 \%$ of the trend, respectively. Finally, when we look into this last partition we find that, together with the middle and the upper classes, the reduction in inequality within retired households again plays a significant part in accounting for the trend in uncontaminated inequality.

Before we finish, one may ask how we can explain the reduction of household expenditures inequality in spite of the rise in unemployment rates. In this paper we have seen that the number of persons living in households headed by an unemployed person has remained practically constant, representing $5.5 \%$ of the population in 1990-1991. But we know that unemployment is particularly large among the young, and we have seen that households with young dependents between 17 and 30 years old have experienced a considerable increase. As a matter of fact, Del Río and Ruiz-Castillo (1997b) find that, in spite of the fact that those looking for a first job have lost relative positions during the 1980s, the young unemployed who live as dependants in the parental home are not far from the national mean in the distribution of equivalised household expenditures, and better off than any other unemployed subgroup. This is in line with Revenga (1991)'s suggestion that these living arrangements might have helped offset the negative effects that, otherwise, increasing unemployment rates among the young could have caused in overall inequality ${ }^{15}$. In any case, as we have seen, the subgroup mean expenditures index for households headed by an unemployed has increased slightly from 72 to 78 during the 1980s, contributing to a decrease in between-group inequality. Moreover, it should be noted that this is one of the few subgroups for which inequality has increased.

However, we must take into account that many of the young persons remaining in the parental home are employed and their earnings are part of total household income. Total household income is also affected by the increase in labor participation of married women and the fact that many beneficiaries of old

\footnotetext{
15 One of the conclusions in Martínez and Ruiz-Castillo (2001), where the decisions to work, to study and to remain or not in the parental house are jointly modelled, is that parents help their young offspring through corresidence when the later do not have a job or are studying.
} 
age and disability pensions live as dependents in their children's homes. More research on the income side is needed to determine whether the final picture is one of an increase in labor and/or market personal earnings inequality, compensated by changes in female labor participation, living arrangements and an increasingly generous system of public transfers which lead to the present reduction in household expenditures inequality.

\section{References}

Alvarez, C., Ayala, L., Iriondo, I., Martínez, R., Palacio, J.I., Ruiz-Huerta, J. (1996) La distribución funcional y personal de la renta en España. Consejo Económico y Social, Madrid

Atkinson, A.B., Rainwater, L., Smeeding, T. (1995) Income Distribution in OECD Countries: the Evidence from the Luxembourg Income Study (LIS). OECD, Paris

Boldrin, M., Jimenez, S., Peracchi, F. (1998) Social Security and Retirement in Spain. In: Wise, D., Gruber, J. (eds.) Social Security : An International Perspective. NBER and University of Chicago Press

Bourguignon, F. (1979) Descomposable income inequality measures. Econometrica 47: 901-920

Borooah, V., Collins, G. (1995) Was There a Regional Dimension to Changes in Income Inequality in the UK over 1982-1992? An Analysis Based on a Joint Decomposition of Income by Region and Employment Status. The Microsimulation Unit, Department of Applied Economics, University of Cambridge, DAE Working Papers Number MU 9507

Buhmann, B., Rainwater, L., Schmaus, G., Smeeding, T. (1988) Equivalence Scales, Well-Being, Inequality and Poverty: Sensitivity Estimates Across Ten Countries Using the Luxembourg Income Study Database. Review of Income and Wealth 34: 115-142

Coulter, F., Cowell, F., Jenkins, S. (1992a) Differences in Needs and Assessment of Income Distributions. Bulletin of Economic Research 44: 77-124

Coulter, F., Cowell, F., Jenkins, S. (1992b) Equivalence Scale Relativities and the Extent of Inequality and Poverty. Economic Journal 102: 1067-1082

Cowell, F. (1984) The Structure of American Income Inequality. Review of Income and Wealth 30: 351-375

Cowell, F., Jenkins, S. (1995) How Much Inequality Can We Explain? A Methodology and an Application to the USA. Economic Journal 105: 421-430

Cowell, F.A., Kuga, K. (1981) Inequality Measurement: An Axiomatic Approach. European Economic Review 15: 287-305

Cutler, D., Katz, L. (1992) Rising Inequality? Changes in the Distribution of Income and Consumption in the 1980s. American Economic Review, Paper and Proceedings 82: 546-551

Danziger, S., Taussing, M. (1979) The Income Unit and the Anatomy of the Income Distribution. Review of Income And Wealth 79: 365-375

Del Rio, C., Ruiz-Castillo, J. (1996) Ordenaciones de bienestar e inferencia estadística. El caso de las EPF de 1980-81 y 1990-91. In: ”La desigualdad de recursos. Segundo Simposio sobre la distribución de la renta y la riqueza. Fundación Argentaria, Colección Igualdad, Vol. VI, 9-44

Del Río, C., Ruiz-Castillo, J. (1997a) An Inequality Decomposition method Which Minimizes Equivalence Scales ‘Contamination’ Problems. Working Paper 97-42, Economic Series 19, Universidad Carlos III de Madrid

Del Río, C., Ruiz-Castillo, J. (1997b) Demographic Trends and Living Standards. Working Paper 97-67, Economic Series 33, Universidad Carlos III de Madrid

Del Rio, C., Ruiz-Castillo, J. (2001) Intermediate Inequality and Welfare. The Case of Spain, 1980-81 to 1990-91. Review of Income and Wealth 47(2): 221-237

Del Río, C., Sastre, M., Ruiz-Castillo, J. (1999) La desigualdad del gasto en España en términos reales en 1973-74, 1980-81 y 1990-91. mimeo

Gottschalk, P., Smeeding, T. (1997) Crossnational Comparisons of Earnings and Income Inequality. Journal of Economic Literature XXXV: 633-686

Gouveia, M., Tavares, J. (1995) The Distribution of Household Income and Expenditure in Portugal: 1980 and 1990. Review of Income and Wealth 41(1): 1-17 
INE (1996) Desigualdad y pobreza en España. Estudio basado en las Encuestas de Presupuestos Familiares de 1973-74, 1980-81 y 1990-91. INE, Madrid

Jäntti, M. (1997) Inequality in Five Countries in the 1980s: The Role of Demographic Shifts, Markets and Government Policies. Economica 64: 415-40

Jenkins, S.P. (1995) Accounting for Inequality Trends: Decomposition Analyses for the UK, 1971-86. Economica 62: 29-63

Jenkins, S.P., Cowell, F.A. (1994) Parametric Equivalence Scales and Scale Relativities. The Economic Journal 104: 891-900

Martínez, M., Ruiz-Castillo, J. (2001) The Decisions by Spanish Youth. Journal of Population Economics (forthcoming)

Mookherjee, D., Shorrocks, A. (1982) A Decomposition Analysis of the Trend in UK Income Inequality. Economic Journal 92: 886-902

Pena, B. (1996) Distribución personal de la renta en España: correcciones y modelización de la información básica, desigualdad y análisis. Ed. Pirámide. Madrid

Revenga, A. (1991) La liberalización económica y la distribución de la renta: la experiencia española. Moneda y Crédito 193: 179-224

Rodrigues, C.F. (1993) Measurement and Decomposition of Inequality in Portugal, 1980/81-1990/91. Department of Applied Economics, University of Cambridge, E.S.R.C. Discussion Paper, MU 9302

Ruiz-Castillo, J. (1995a) Income Distribution and Social Welfare: A Review Essay. Investigaciones Económicas XIX: 3-34

Ruiz-Castillo, J. (1995b) The Anatomy of Money and Real Inequality in Spain, 1973-74 to 1980-81. Journal of Income Distribution 5: 265-281

Ruiz-Castillo, J. (1998) A Simplified Model for Social Welfare Analysis. An Application to Spain, 1973-74 to 1980-81. Review of Income and Wealth 44(1): 123-141

Ruiz-Castillo, J. (1999) La importancia de los aspectos microeconómicos en las Encuestas de Hogares. Tercer Taller Regional. Medición del Gasto en las Encuestas de Hogares, CEPAL

Ruiz-Castillo, J., Higuera, C., Izquierdo, M., Sastre, M. (1999) Indices de precios para las EPF de 1973-74, 1980-81 y 1990-91 con base en 1976, 1983 y 1992. mimeo, available in http://www.eco.uc3m.es/investigacion/epf.html.

San Juan, C (1995a) Financiación agraria y competitividad. In: La economía española en un escenario abierto. Fundación Argentaria, Madrid, 345-395

San Juan, C (1995b) La Política agraria común y sus efectos en la convergencia real de España en la Unión Europea. Papeles de Economía Española 63: 286-305

Shorrocks, A.F. (1980) The Class of Additively Decomposable Inequality Measures. Econometrica 48: $613-625$

Shorrocks, A.F. (1984) Inequality Decomposition by Population Subgroups. Econometrica 52: 13691388

Shorrocks, A.F. (1995) On Income Distribution Comparisons for Heterogeneous Populations. University of Essex, Discussion Paper Series, No. 447

Tsakloglou, P. (1993) Aspects of Inequality in Greece. Measurement, Decomposition and Intertemporal Change: 1974, 1982. Journal of Development Economics 40: 53-74 